\title{
Malignant pleural mesothelioma in a nuclear engineer
}

\author{
M HUNCHAREK,' K SMITH, ${ }^{2}$ R MILATOU ${ }^{3}$ \\ From the Canadian Tumor Reference Center,' National Cancer Institute of Canada, Ottawa, Canada; \\ Department of Epidemiology and Public Health, ${ }^{2}$ Yale University School of Medicine, and Department of \\ Biosafety, ${ }^{3}$ Yale University Health Services, New Haven, Conn, USA
}

Malignant pleural mesothelioma accounts for a large proportion of deaths among occupational cohorts exposed to asbestos. ${ }^{1-4}$ Of particular interest are recent reports of a high risk of mesothelioma among occupational groups previously thought to be at low risk for developing this neoplasm. ${ }^{5}$ In the present report we present a case of pleural mesothelioma associated with "bystander" exposure to asbestos in a nuclear engineer. To our knowledge, this is the first report of the disease occurring in a member of this occupational group after work related exposure to asbestos.

\section{Case report}

A previously healthy 49 year old man developed acute mild right chest pain and was admitted to hospital in February 1979. Chest $x$ ray films showed pleural fluid. A thoracentesis was carried out and the fluid was found to be benign. The patient was discharged and followed up on an outpatient basis.

Subsequent chest $x$ ray films continued to show pleural effusion (March-May 1979). In July 1979 a second thoracentesis was positive for malignancy but the aetiology was unclear. In August fluoroscopy showed several 1-3 mm parietal pleural plaques. Pleural biopsy showed a malignant neoplasm with numerous psammoma bodies consistent with adenocarcinoma or malignant mesothelioma. There was no evidence of a primary tumour outside the lung. In October 1979 the patient underwent right pleural pneumonectomy, where the tumour was found to affect the parietal pleura of the lower chest wall on its mediastinal and diaphragmatic surfaces. Microscopically, sections of the right lung showed a multifocal pleural process characterised by malignant cells growing in an epithelial like fashion producing papillae. The lung was free of disease. PAS stains for mucin were negative. (No other histochemical stains of the tumour were performed.) Cytological and histological features were consistent with malignant pleural mesothelioma. Postoperatively, the patient

Accepted 22 June 1987 received radiotherapy followed by chemotherapy (November 1979-January 1980).

The patient was well and active until December 1980 when he developed increasing shortness of breath and fever. He was admitted to hospital and was noted to have pericarditis with small pulsus paradoxicus, Kussmaul's sign, and moderate pericardial effusion. After an unsuccessful attempt at pericardiocentesis, the patient underwent a pericardial window and pericardial biopsy. The biopsy specimen was positive for malignant mesothelioma.

After discharge, he developed progressive shortness of breath, continued fever, and nocturnal dyspnoea. He was readmitted to hospital in January 1981, given supportive care, and died in late January 1981. Necropsy showed the presence of malignant mesothelioma of the epithelial subtype in the mediastinum, diaphragm, and pericardium with invasion into the myocardium.

This patient was employed for 27 years as a research nuclear engineer engaged in the design and development of nuclear reactors, more specifically the design of sodium cooled atomic power stations. Interestingly, he reported no history of exposure to asbestos to the physician who cared for him during the evaluation and treatment of his mesothelioma. This is understandable since he did not work directly with asbestos. Previous occupational history included work as a carpenter's helper for four months in 1950 (age 20) but no known exposure to asbestos occurred.

On detailed questioning of coworkers, it was discovered that the sodium cooled reactors, on which this patient worked, were insulated with asbestos, including moulded pipe coverings, asbestos valve packing, and powdered asbestos that was made into "mud" for repairing damaged insulation. One coworker stated that he sawed asbestos insulation while working on the sodium cooled test reactors, which created substantial quantities of dust. According to this individual, the research engineers, including this patient, were often present during these procedures while observing the functioning of the reactors.

An additional coworker described the dust in the reactor building as so thick "that you couldn't see 
across the building." Asbestos fibres were also described as being constantly present on the building floor. Since the test systems on which this patient worked underwent continuous modification, workplace contamination with asbestos fibres was commonplace.

Interestingly, a third coworker of this patient reportedly worked at the same job site for five years, building the sodium reactor test equipment. He was engaged in remachining pipes, fittings, valves, and valve assemblies insulated with asbestos. This work required stripping and removal of the insulation before the machining. Twenty years after initial exposure to asbestos in the coworker, he developed pleural mesothelioma and died within a year of diagnosis.

\section{Discussion}

A major problem with the epidemiological analyses of malignant mesothelioma in both occupational and non-occupational settings is obtaining adequate documentation of possible exposure to asbestos. In "household" or neighbourhood (environmental) settings exposure to asbestos often goes unnoticed and it is only through aggressive questioning and investigation that positive exposure histories are found. It now appears that the same may occur among occupational groups exposed "indirectly" (secondarily) to asbestos products.

Although the association of mesothelioma with exposure to asbestos was described in $1960^{\circ}$ and although various occupational groups have been identified as being "at risk" of developing this tumour due to exposure to asbestos, recent evidence suggests that other occupational groups (previously thought not to be at high risk) may also be at risk of developing mesothelioma. For instance, Schenker et al recently completed a case-control study of deaths from mesothelioma among United States railroad workers. ${ }^{5}$ Analysis of death certificate diagnoses for 15059 deaths reported by the railroad retirement board showed 20 cases of mesothelioma that were strongly associated with asbestos exposed job categories. As the authors point out, the importance of this study is the "characterisation and quantitation" of a risk of mesothelioma among a previously unstudied occupational group. Of particular interest is the fact that since Schenker's analysis relied on death certificate diagnosis only, the true number of cases of this tumour among this group is probably larger.

Two additional recent reports highlight the problems associated with unexpected exposures to asbestos and the occurrence of mesothelioma. ${ }^{78}$ The first study by Paci et al reviewed histological specimens from suspected cases of malignant mesothelioma diagnosed between 1979 and 1984 in the pathology department of the University of Florence. Of 13 cases identified, six worked in the textile industry as rag sorters. None of these subjects was able to recall previous exposure to asbestos.

A second study of the reprocessed textile industry in Italy by Quinn et al suggests that an excess risk of lung cancer and mesothelioma exists among workers in this industry. ${ }^{8}$ A follow up report showed that polypropylene bags which previously contained asbestos were used in two of the 13 textile reprocessing establishments studied. ${ }^{7}$ These bags were cut and used to cover bales of rags before world wide distribution. It was subsequently determined that workers were exposed to asbestos fibres while handling these bags. This illustrates the possible existence of a risk of cancer due to "secondary" exposure to asbestos among workers in a non-asbestos industry.

In the case of the nuclear engineer with pleural mesothelioma presented here it appears clear that he was exposed intermittently and secondarily to asbestos fibres during the course of his employment. Since information provided by coworkers established that high levels of asbestos dust were periodically present at the worksite, nuclear engineering personnel may be at substantially increased risk of developing mesothelioma under such circumstances due to "bystander" exposure.

We gratefully acknowledge the support of Dr W T E McCaughey.

Requests for reprints to: M Huncharek, MPH, Box 487, Boston University School of Medicine, 80 East Concord Street, Boston, Mass 02118, USA.

\section{References}

1 Selikoff IJ, Hammond EC, Seidman H. Mortality experience of insulation workers in the United States and Canada. Ann NY Acad Sci 1979;330:91-116.

2 Newhouse M. Epidemiology of asbestos related tumors. Semin Oncol 1981;8:250-7.

3 Tagnon I, Blot WJ, Stroube RB, et al. Mesothelioma associated with the shipbuilding industry in coastal Virginia. Cancer Res 1980;40:3875-9.

4 Aisner J, Wiernik PH. Malignant mesothelioma; current status and future prospects. Chest 1978;74:438-44.

5 Schenker MB, Garshick E, Munoz A, Woskie SR, Speizer FE. A population based case-control study of mesothelioma deaths among US railroad workers. Am Rev Respir Dis 1986;134: 461-5.

6 Wagner JC, Sleggs CA, Marchand P. Diffuse pleural mesothelioma and asbestos exposure in the Northwest Cape Province. Br J Ind Med 1960;17:260-71.

7 Paci E, Dini S, Buiatti E, Constantini AS, Lenzi S, Zappa M. Malignant mesothelioma in non-asbestos textile workers in Florence. Am J Ind Med 1987;11:249-54.

8 Quinn MM, Kriebel D, Buiatti E, et al. An asbestos hazard in the reprocessed textile industry. Am J Ind Med 1987;11:255-66. 